\title{
A STUDY ON FORCED DEGRADATION AND VALIDATION OF STABILITY INDICATING RP-HPLC METHOD FOR DETERMINATION OF BENZALKONIUM CHLORIDE IN AZELASTINE HYDROCHORIDE PHARMACEUTICAL OPHTHALMIC FORMULATION
}

\author{
PRATIK KUMAR GUPTA*, VIBHA CHATURVEDI \\ Department of Chemistry, Mewar University, Chittorgarh, Rajasthan, India. Email: pkpipraiya@gmail.com \\ Received: 30 July 2017, Revised and Accepted: 29 August 2017
}

ABSTRACT

Objective: This study was designed to conduct forced degradation and validation studies for determination the benzalkonium chloride (BKC) as major homologues form in azelastine hydrochloride pharmaceutical ophthalmic formulation by a novel stability indicating reverse phase high-performance liquid chromatographic method (RP-HPLC).

Methods: Forced degradation study and validation were carried out with a analytical approach of reverse phase chromatographic analysis with C18, cosmosil ( $250 \mathrm{~mm} \times 4.6 \mathrm{~mm}$ i.d. $\times 5 \mu \mathrm{m})$ column using mobile phase consisting acetonitrile - buffer of $\mathrm{pH} 5.0 \mathrm{with} 5 \mathrm{~N} \mathrm{NaOH}(45: 55 \% \mathrm{v} / \mathrm{v})$ at a flow rate of $1.5 \mathrm{ml}$ per minute. Column temperature was maintained at $25^{\circ} \mathrm{C}$ and detection wavelength was $210 \mathrm{~nm}$. By using these chromatographic conditions of method, two major homologues of benzalkonium chloride were separated without any interference of drug components and exciepients.

Results: Forced degradation studies were carried out as per ICH guidelines and established a stability indicating property of a method .The method was found linear in concentration range $40 \mu \mathrm{g} / \mathrm{ml}$ to $60 \mu \mathrm{g} / \mathrm{ml}(50 \mu \mathrm{g} / \mathrm{ml} \pm 20 \%)$, correlation coefficient was found 0.999 . The recovery was found to be $99.2 \%, 100.7 \%$ and $101.4 \%$ at $\pm 30 \%$ of target concentration. The $\%$ RSD for method precision and intermediate precision were found $0.28 \%$ and $0.30 \%$ respectively. The method was found specific, selective, precise, accurate, linear, robust and stability indicating for quantification benzalkonium chloride in azelastine pharmaceutical ophthalmic formulation.

Conclusion: The method has been found successful for determination of BKC pharmaceutical formulation and validated for all the parameters of validation and found within the acceptance criteria as per ICH guideline Q2R1.

Keywords: Benzalkonium chloride content, HPLC, BKC, Preservative, ophthalmic solution, forced degradation.

(c) 2017 The Authors. Published by Innovare Academic Sciences Pvt Ltd. This is an open access article under the CC BY license (http://creativecommons. org/licenses/by/4. 0/) DOI: http://dx.doi.org/10.22159/ajpcr.2017.v10i11.21701

\section{INTRODUCTION}

Benzalkonium chloride (BKC) is a preservative most commonly found in ophthalmic and nasal formulations [1]. BKC is a quaternary ammonium compound, a mixture of alkylbenzyldimethylammonium chlorides containing the formula [C6H5CH2N(CH3)2R]Cl, where $\mathrm{R}$ is an alkyl group varying from $\mathrm{C} 8 \mathrm{H} 17$ to $\mathrm{C} 18 \mathrm{H} 37$ (Fig. 1) [2].

As an antimicrobial agent, BKC can be safely used at concentrations from $0.002 \%$ to $0.02 \%$ but it can be up to $0.2 \%$ depending on various factors in ophthalmic drug products [3]. BKC is a common preservative used in ophthalmic drug products with the concentrations range from $0.004 \%$ to $0.01 \%$. Higher concentrations can be caustic [4] and it may cause irreversible damage to the corneal endothelium. Various researches on BKC have found no direct relation between the use of $\mathrm{BKC}$ in concentrations below $0.1 \%$ in nasal sprays and drug-induced rhinitis [5]. BKC solutions act as biocidal agents with a fairly long duration of action. They are strongly active against some viruses, bacteria, fungi, and protozoa. Bacterial spores are considered to be more resistant. These BKC solutions are bacteriostatic or bactericidal according to their concentration. Sensitivity of Gram-positive bacteria is more than other.

Azelastine hydrochloride pharmaceutical ophthalmic formulation is relatively selective $\mathrm{H} 1$ receptor antagonist for topical administration to eyes. Azelastine hydrochloride has antihistaminic therapeutic effects vulnerable providing immediate relief, mast cell stabilization providing early-phase intervention, and inhibition of expression and activation of anti-inflammatory mediators which characterize the late phase of the immune reaction [6]. Its chemical name is $( \pm)-1-(2 \mathrm{H})$-phthalazinone,4[(4chlorophenyl) methyl]-2-(hexahydro-1-methyl-1H-azepin-4-yl)-, monohydrochloride. Its molecular formula is $\mathrm{C}_{22} \mathrm{H}_{24} \mathrm{ClN}_{3} \mathrm{O} \bullet \mathrm{HCl}$ with the following chemical structure (Fig. 2).

A number of analytical methods have been reported for the estimation of BKC in various products including ophthalmic preparations [7-23]. However, there was no method available for estimation of BKC in azelastine hydrochloride ophthalmic formulations.

Several chromatographic methods have been developed for the determination of BKC in the past. The quantification of BKC using these methods in ophthalmic solutions was not suitable for our product of interest. Low detection sensitivity because of high range of wavelength utilization, long run-time and use of reversed-phase $\mathrm{CN}$ column is critical with some types of ophthalmic drug products. As our ophthalmic solution contained azelastine as active ingredient and other excipients, injection at high concentration was not suggested with the CN column. The ideal method should have a high sensitivity of detector, minimum sample concetrationion to maintain column robustness, and optimized low run-time analysis. Dudkiewicz-Wilczynska et al. reported used phenomenex Luna CN, $250 \mathrm{~mm} \times 4.6 \mathrm{~mm} \times 5 \mu \mathrm{m}$ column and $0.075 \mathrm{M}$ acetate buffer, pH5.0 with acetonitrile in a ratio of $(55: 45 \mathrm{v} / \mathrm{v})$ and flow rate was $1.5 \mathrm{ml} /$ minute. The detecton wavelength is $262 \mathrm{~nm}$ and column temperature is $25^{\circ} \mathrm{C}[22]$. 


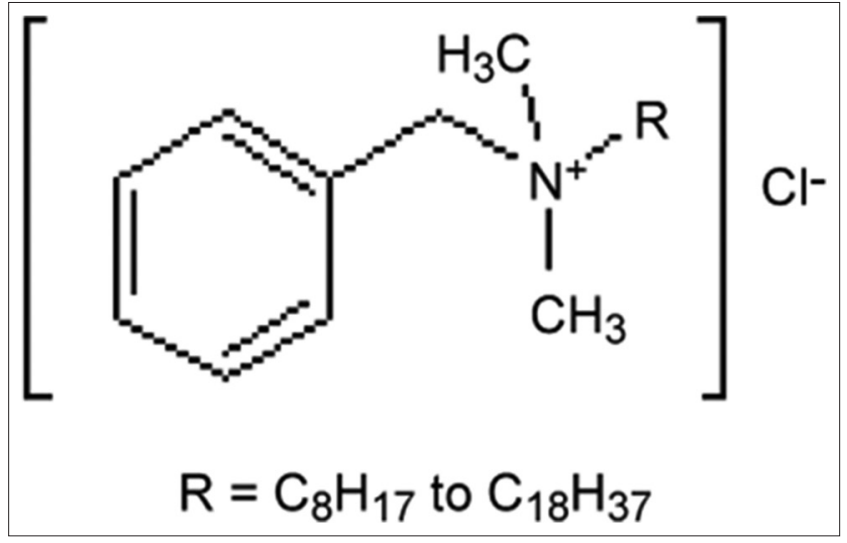

Fig. 1: Chemical structure of benzalkonium chloride

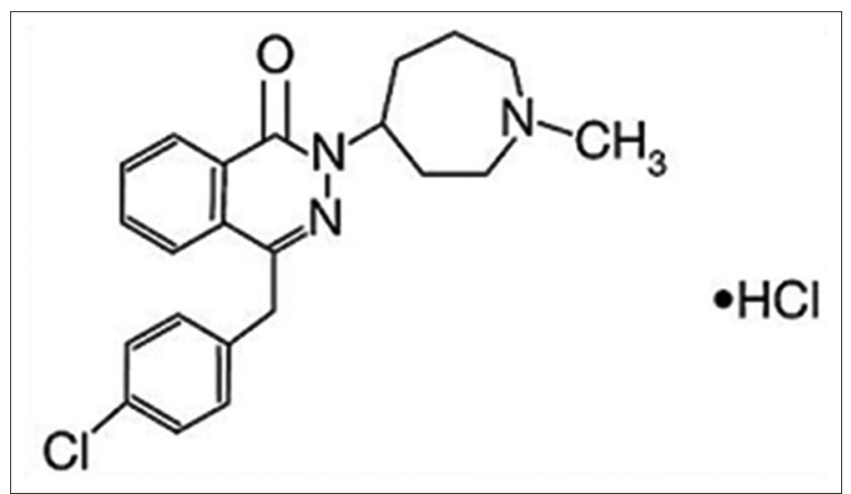

Fig. 2: Chemical structure of azelastine hydrochloride

Louis-Philppe et al. reported that column waters symmetry shield RP18 $(75 \mathrm{~mm} \times 4.6 \mathrm{~mm} \times 3.5 \mu \mathrm{m})$ was chosen. The mobile phase was a ratio $(68: 32 \mathrm{v} / \mathrm{v})$ of methanol-potassium phosphate $(\mathrm{pH} 3.0,7.5 \mathrm{mM})$. The flow rate was $1.0 \mathrm{ml} /$ minute at column oven temperature $50^{\circ} \mathrm{C}$. The wavelength was $208 \mathrm{~nm}$ and injection volumn was $20 \mu \mathrm{L}$ [23]. The main objective of this work was the determination of BKC in azelastine hydrochloride ophthalmic solution by reverse phase high-performance liquid chromatographic (HPLC) method development, validation, and robustness.

\section{METHODS}

\section{Reagent and chemicals}

The standard of BKC $50 \%$ solution with $50 \%$ purity was provided by fisher scientific, Mumbai. HPLC grade acetonitrile, water, and HCl (AR grade) were obtained from Merck, Mumbai. $\mathrm{H}_{2} \mathrm{O}_{2}$, sodium hydroxide, orthophasphoric acid were obtained from fisher scientific, Mumbai. All regents were used without any further purification. All components were obtained from commercial sources and used as received.

\section{Instrumentation}

Analysis was performed on an waters 2695 HPLC system and Shimadzu HPLC system equipped ultraviolet (UV) and photo diode array detector equipped quaternary solvent delivery pump, automatic sample injector, column thermostat. The data acquisition and analysis were performed using Empower software and LC solution.

\section{Method and conditions}

The HPLC equipped UV/photo diode array detector was used as analytical technique for the determination of BKC homologs in azelastine ophthalmic solution. Detector response versus sample preparation was optimized in series of experiments where other parameters such as column selection, mobile phase, column temperature, and different diluents were analyzed. In addition, some set of experiments have been conducted for optimization of sample concentration and standard solution concentration.

Buffer was prepared by dissolving $5.0 \mathrm{ml}$ of orthophosphoric acid in $1000 \mathrm{ml}$ of water and added $1.0 \mathrm{ml}$ of triethyl amine to this solution. The $\mathrm{pH}$ of buffer was adjusted to 5.0 with $5 \mathrm{~N} \mathrm{NaOH}$ solutions. The mobile phase consisted of buffer $\mathrm{pH}$ 5.0: Acetonitrile (55: 45, v/v) was filtered by $0.45 \mu$ membrane filter and degassed under vacuum before use. The flow rate of pump for mobile phase was $1.5 \mathrm{ml} /$ minute. The UV detection was performd at $210 \mathrm{~nm}$ and the injection volume was 20-30 $\mu \mathrm{L}$. The HPLC system equipped with maintaining column oven temperature with $25^{\circ} \mathrm{C}$. The reverse phase column cosmosil C18, $250 \mathrm{~mm}$ length $\times 4.6 \mathrm{~mm}$ I.D. $\times 5 \mu \mathrm{m}$ particle size was used for optimization of chromatographic conditions.

\section{Standard and sample solution preparation Standard preparation}

A working standard solution of BKC $(50 \mu \mathrm{g} / \mathrm{ml})$ was prepared using diluent for assay determination.

\section{Sample preparation}

Ophthalmic solution containing BKC $(50 \mu \mathrm{g} / \mathrm{ml})$ was prepared using diluent.

\section{System suitability parameters}

Five replicates injections of standard, and the system suitability check was doe as follows.

1. The percentage relative standard deviation (RSD) of the total area of homologues peaks should be not more than 2.0.

2. The theoretical plates of both peaks should be not $<2000$.

3. The tailing factor of both peaks should be not more than 2.5 .

\section{Method validation}

The method validation $[24,25]$ for BKC determination was performed as per ICH guideline by determining the parameters: Specificity, precision, linearity, accuracy or recovery, robustness, and forced degradation studies.

\section{Specificity}

Specificity is the ability to assess unequivocally the analyte in the presence of components which may be expected to be present. The specificity of method was determined by analyzing the solutions such as diluent, standard solution of BKC, and ophthalmic sample solution of $100 \%$ level. Each of the solution is injected on HPLC equipped with photo diode array detector for peak purity analysis and chromatograms were recorded.

\section{Instrument precision}

System precision was established by injecting five replicate injections of standard solution of BKC $(50 \mu \mathrm{g} / \mathrm{ml})$. The peak areas of sum of homolog's peaks, tailing factor, and theoretical plates of each homolog's were evaluated.

\section{Method precision}

The precision of an analytical procedure expresses the closeness of agreement (degree of scatter) between a series of measurements obtained from multiple sampling of the same homogeneous sample under the prescribed conditions. Method precision was determined by analysis of BKC in six ophthalmic solution preparations and each sample was injected in duplicate. For each sample, chromatograms were recorded. The percentage RSD of six assay of sample preparation was calculated and found $<2.0$.

\section{Intermediate precision}

Intermediate precision expresses within - laboratories variations: Different days, different analysts, different equipment, etc. The main objective of intermediate precision is to find out the effect of random events on the analytical method so that analysis of sample on different column, different day and different instrument. 


\section{Accuracy}

The accuracy of an analytical procedure expresses the closeness of agreement between the value which is accepted either as a conventional true value or an accepted reference value and the value found. Accuracy of method is defined as the closeness of measured value to the true value for sample. Accuracy of a HPLC method was carried out a three different level, i.e. $\pm 30 \%$ of level claim, so that, $70 \%$, $100 \%$, and $130 \%$ of BKC. Three samples were prepared at each concentration level and injected in duplicate.

\section{Linearity/range}

The linearity of an analytical procedure is its ability (within a given range) to obtain test results which are directly proportional to the concentration (amount) of analyte in the sample. The range of an analytical procedure is the interval between the upper and lower concentration (amounts) of analyte in the sample (including these concentrations) for which it has been demonstrated that the analytical procedure has a suitable level of precision, accuracy, and linearity. Linearity was performed to verify detector limit in minimum of five concentration level between $\pm 20 \%$ of $100 \%$ level. A minimum five concentration level of standard solution was injected in duplicate. As a outcome of linearity slope, Y- inetcept and correlation coefficient have been calculated.

\section{Robustness}

The robustness of an analytical procedure is a measure of its capacity to remain unaffected by small, but deliberate variations in method parameters and provides an indication of its reliability during normal usage.

\section{Deliverable changes in method parameters}

The study has been conducted for effect of small variation in method parameters for optimization of method such as:

1. Column oven temperature variation $\left( \pm 2^{\circ} \mathrm{C}\right)$

2. Variation in flow rate $( \pm 10 \%)$

3. Variation in $\mathrm{pH}$ of buffer ( \pm 0.2 unit)

4. Variation of mobile phase composition $( \pm 1 \%)$.

The standard solution of BKC and sample solution were injected for each of the robustness conditions (such as column temperature $\pm 2^{\circ} \mathrm{C}$, $\mathrm{pH}$ of buffer \pm 0.2 unit and mobile phase composition $\pm 1 \%$ ).

\section{Forced degradation studies}

For proving stability indicating strength of a method, a forced degradation studies have been conducted [26,27]. Stability indicating method means that our method is capable of accurate and precise measurement of active ingredients (drug substance an drug products) free from process impurities, excipients, and degradation products.

\section{Acid degradation}

$5 \mathrm{ml}$ of sample solution was transferred into volumetric flask of $20 \mathrm{ml}$. Added $2 \mathrm{ml}$ of $1 \mathrm{M} \mathrm{HCl}$ to this solution and flask was kept this solution at $80^{\circ} \mathrm{C}$ for $2 \mathrm{hrs}$ in water bath. After $2 \mathrm{hrs}$, sample withdrawn and allow to come at room temperature, neutralized by $1 \mathrm{M} \mathrm{NaOH}$ solution and diluted to final concentration of $50 \mu \mathrm{g} / \mathrm{ml}$, and injected immediately.

\section{Alkali degradation}

$5 \mathrm{ml}$ of sample solution was transferred into volumetric flask of $20 \mathrm{ml}$. Added $2 \mathrm{ml}$ of $1 \mathrm{M} \mathrm{NaOH}$ to this solution and flask was kept this solution at $80^{\circ} \mathrm{C}$ for $2 \mathrm{hrs}$ in water bath. After $2 \mathrm{hrs}$, sample withdrawn and allow to come at room temperature, neutralized by $1 \mathrm{M} \mathrm{HCl}$ solution and diluted to final concentration of $50 \mu \mathrm{g} / \mathrm{ml}$, and injected immediately.

\section{Oxidative degradation}

$5 \mathrm{ml}$ of sample solution was transferred into volumetric flask of $20 \mathrm{ml}$. Added $2 \mathrm{ml}$ of $\mathrm{H}_{2} \mathrm{O}_{2}$ to this solution and flask was kept at $80^{\circ} \mathrm{C}$ for 2 hrs in water bath. After 2 hrs, sample withdrawn and diluted to final concentration of $50 \mu \mathrm{g} / \mathrm{ml}$, and injected.

\section{Thermal degradation}

$5 \mathrm{ml}$ of sample solution was transferred into volumetric flask of $20 \mathrm{ml}$. Flask was kept at $80^{\circ} \mathrm{C}$ for 2 hrs in water bath. After 2 hrs, sample withdrawn and diluted to final concentration of $50 \mu \mathrm{g} / \mathrm{ml}$ and injected.

\section{RESULTS AND DISCUSSION}

\section{Method development and optimization of chromatographic conditions}

Primary objective of this study is determination of BKC content in azelastine hydrochloride ophthalmic solution. As per literature search, previously various chromatographic methods for BKC determination have been reported. Different column have been used such as reverse phase columns (C8 or C18), CN column. Various columns such as L10 or $\mathrm{CN}$ packing, L1(C18) were used for determination of BKC by HPLC. Mobile phase consisting of aqueous buffer $\mathrm{pH}$ 3.0-6.5 were used with acetonitrile or methanol in different ratio [27]. As per effects of various factors were analyzed for separation process for determination of conditions of BKC homologues. The influence of various column types, mobile phase ratio and column oven temperature, flow rate, and different wavelength were summarized.

After optimization of various column and buffer with different $\mathrm{pH}$ range with mobile phase consisting of acetonitrile and buffer, finally, we have taken trials on cosmosil column $250 \mathrm{~mm} \times 4.6 \mathrm{~mm} \times 5 \mu \mathrm{m}$ using mobile phase comprising of acetonitrile: Buffer. Various trial have been taken for optimizing the flow rate, mobile phase composition, column temperature, wavelength selection, and finalized the chromatographic condition based on optimization results.

\section{Optimization of sample preparation}

Optimization of sample preparation was a challenging task due to complex composition of ophthalmic formulation. Aqueous diluting solution of sample preparation created foaming and organic mixed diluents created the precipitation of some exciepients. Various diluents were tested, the mobile phase was found to be the best diluents for getting good recovery of total BKC as per ICH guideline criteria. Using this type of sample preparation, recovery results obtained between $98 \%$ and $102 \%$. Typical chromatograms were obtained for mobile phase, standard solution, and a sample solution containing azelastine active drug are presented in Figure, as shown in Figs. 3-5. Two peaks of BKC were found in chromatograms obtained from both standard solution and sample solution.

\section{Method validation} System suitability

The system suitability was performed to for verify the chromatograph at the time of operation by evaluation of chromatographic parameters from six replicate injection of standard solution of BKC $(50 \mu \mathrm{g} / \mathrm{ml}$ in diluent). The results is calculated for each homolog peak of BKC and found acceptable as shown in Table 1.

\section{Specificity}

Specificity of analytical method is its ability to measure accurately and specifically the analyte of interest in the presence of sample

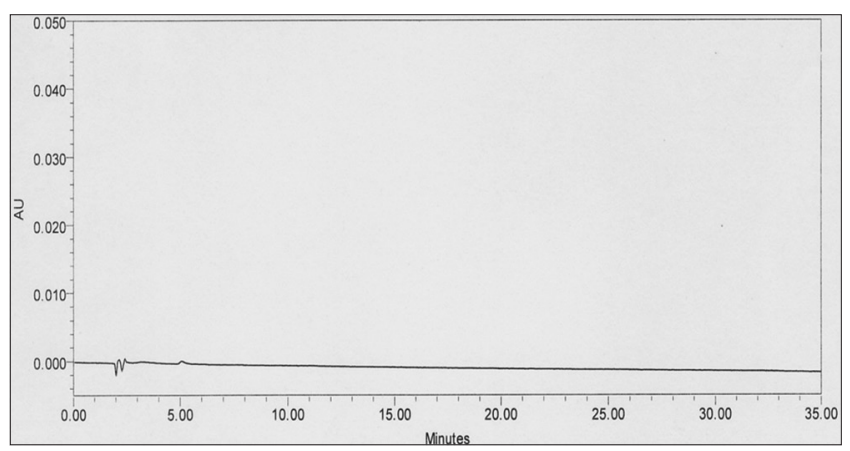

Fig. 3: Representative chromatogram for mobile phase 
matrix, in this study, the ability of the methods to separate the drug from its degradation products without the interference of other sample components indicated the specificity of the developed method. Specificity/selectivity of method was determined by analysis diluents, standard solution, and sample solution. No significance interference was observed at the retention time of homolog peaks of BKC, so that, it is proved that method was specific for analysis of BKC in azelastine hydrochloride ophthalmic solution as shown in Figs. 3-5. In waters, HPLC system peak purity angle should be less than peak purity threshold. In interpretation of chromatograms, for both peaks of BKC, the peak purity angle was less than peak purity threshold. So that, this purity factors declares that there is no coelution of other peaks as shown in Figs. 6 and 7.

\section{Linearity}

The linearity of a method reveals the linear relationship of response against the selected concentration of analyte. Linearity of method was established as linear regression analysis with least square method on standard solution of BKC. Five standard solutions containing BKC

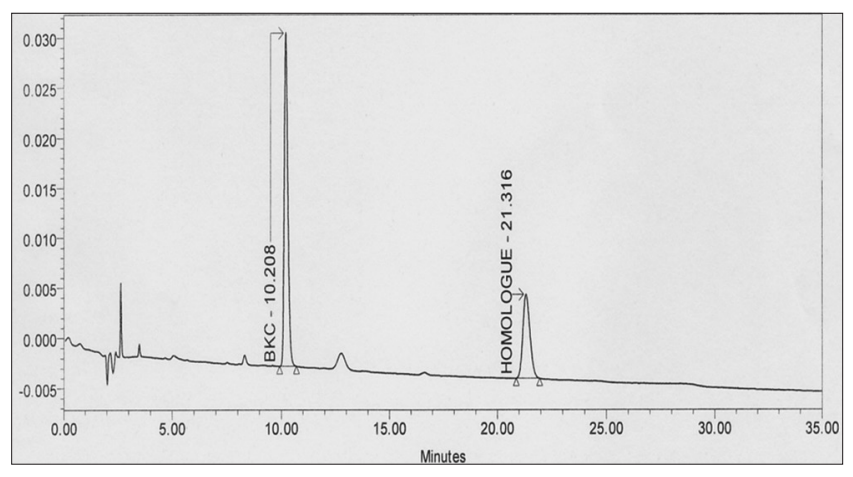

Fig. 4: Representative chromatogram for standard solution

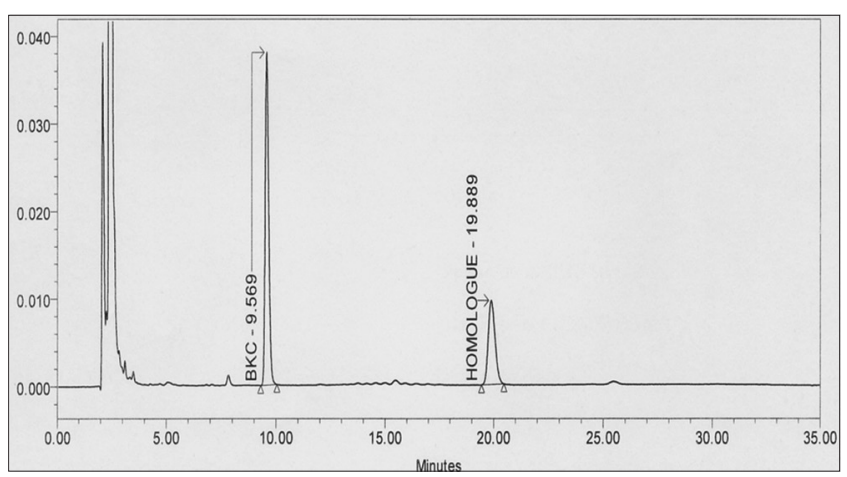

Fig. 5: Representative chromatogram for sample solution

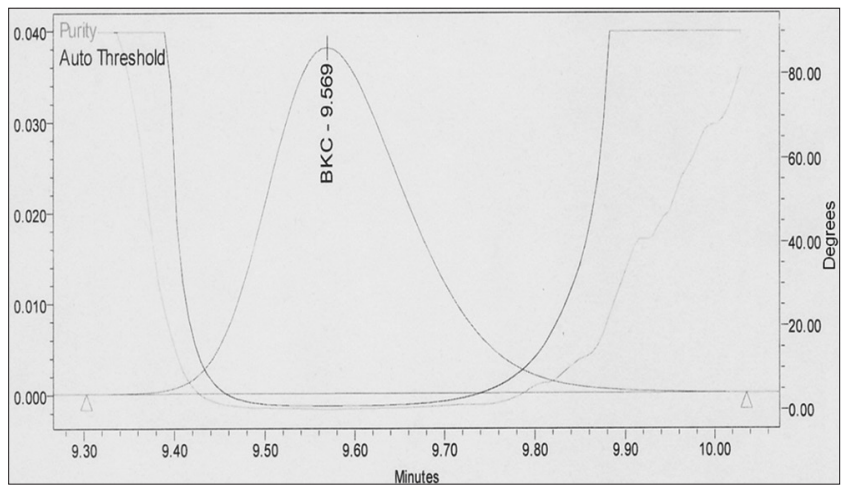

Fig. 6: Peak purity for benzalkonium chloride main peak (waters high-performance liquid chromatographic) comprises $80 \%, 90 \%, 100 \%, 110 \%$, and $120 \%$ of $100 \%$ target level corresponding to $40-60 \mu \mathrm{g} / \mathrm{ml}$. The calibration curve was constructed by plotting peak area versus concentration of benzalkonium chloride. Regression line was established by least squares method. A correlation coefficient of 0.999 was obtained as shown in Fig. 8 and results are discussed in Table 2.

\section{Precision}

The method precision was performed from six sample prepared and injected in duplicate and percentage RSD was obtained within acceptable limit $\leq 2$. Hence, the method is reproducible. The low percentage RSD indicates that the method is precise and reproducible for quantification of BKC content as a preservative in this ophthalmic solution.

Intermediate precision was performed for by injecting six sample preparations on different day, by different column, and different instrument. Percentage assay is calculated for six determinations and percentage RSD was found $0.30 \%$ for intermediate precision as shown in Table 3. There was no significance difference found in intermediate conditions of analysis. So that, we can say that method is precise for intended purpose in different laboratories.

\section{Accuracy/recovery}

Method accuracy was evaluated by preparing the sample solution at $70 \%, 100 \%$, and $130 \%$ level of total benzalkoium chloride labeled claim, i.e. $32.69 \mu \mathrm{g} / \mathrm{ml}, 46.70 \mu \mathrm{g} / \mathrm{ml}$, and $60.71 \mu \mathrm{g} / \mathrm{ml} \mathrm{rrecovery} \mathrm{calculated} \mathrm{for}$ each level are $99.2 \%, 100.7 \%$ and $101.4 \%$.The $\%$ RSD was calculated $0.74 \%, 1.21 \%$ and 0.47 respectively and overall RSD was calculated $0.81 \%$ as shown Table 4 .The results of recovery studies indicated that the method is accurate for estimation of BKC in azelastine ophthalmic formulations.

Table 1: Evaluation of system suitability parameters for standard solution

\begin{tabular}{llll}
\hline Parameters & $\begin{array}{l}\text { Acceptance } \\
\text { criteria }\end{array}$ & BKC peak 1 & BKC peak 2 \\
\hline Retention time & \%RSD & 0.47 & 0.54 \\
Peak area & \%RSD & 0.09 & 0.03 \\
Tailing factor & $<2.5$ & 2.01 & 1.77 \\
Theoretical plates & $>2000$ & 8791 & 12369 \\
Resolution & $>1.5$ & 0 & 19.11 \\
\hline
\end{tabular}

RSD: Relative standard deviation, BKC: Benzalkonium chloride

Table 2: Linearity paratmeter for BKC

\begin{tabular}{ll}
\hline Parameter & Result \\
\hline Correlation coefficient & 0.999 \\
Slope & 35165.141 \\
Y intercept & 4789.000 \\
\hline
\end{tabular}

BKC: Benzalkonium chloride

Table 3: Method precision

\begin{tabular}{lll}
\hline S. No. & Method precision & $\begin{array}{l}\text { Intermediate } \\
\text { precision }\end{array}$ \\
\hline 1 & 100.1 & 99.6 \\
2 & 100.4 & 99.1 \\
3 & 100.6 & 99.7 \\
4 & 100.8 & 99.5 \\
5 & 100.0 & 99.1 \\
6 & 100.2 & 99.8 \\
Mean & 100.3 & 99.5 \\
RSD & 0.28 & 0.30 \\
\% difference & & \\
\hline
\end{tabular}

RSD: Relative standard deviation 


\section{Robustness}

Robustness of proposed method demonstrated a non-significant alteration through the analysis of sample solution and standard solution. The results obtained in robustness conditions were compared

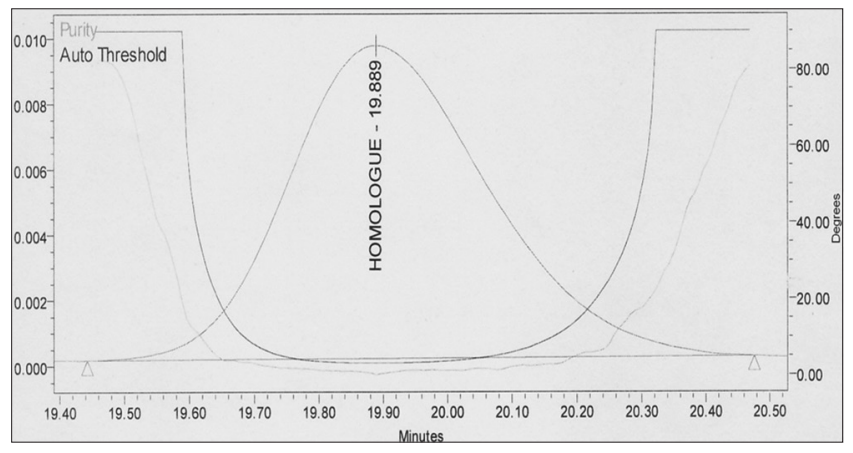

Fig. 7: Peak purity for benzalkonium chloride minor homologue (Waters high-performance liquid chromatographic) with that of optimized method. Robustness analysis of BKC was carried out with some deliberate changes in chromatographic parameters such as wavelength, column temperature, flow rate, changes in mobile phase ratio, and $\mathrm{pH}$ of mobile phase, as representative chromatograms as shown in Figs. 9-13. The system suitability parameters such as theoretical plates, percentage RSD, and tailing factor were found within the limit as shown Table 5.

\section{Forced degradation studies}

BKC content was determined in different stress condition of forced degradation study. No significance interference was found at the retention time of BKC peaks. There was no interference with azelastine peaks at the retention time of BKC peaks. The entire peaks were well separated and can be easily quantified. The peak purity angle was found greater than peak purity threshold so that peak was found pure and homogenous in every stress conditions, due to which, method confirms its specificity and stability indicating property $[20,28,29]$. In alkali degradation, 5.4\% degradation achieved. This method was found stability indicating method. Representative chromatograms are shown in Figs. 14-18 and results are tabulated in Table 6.

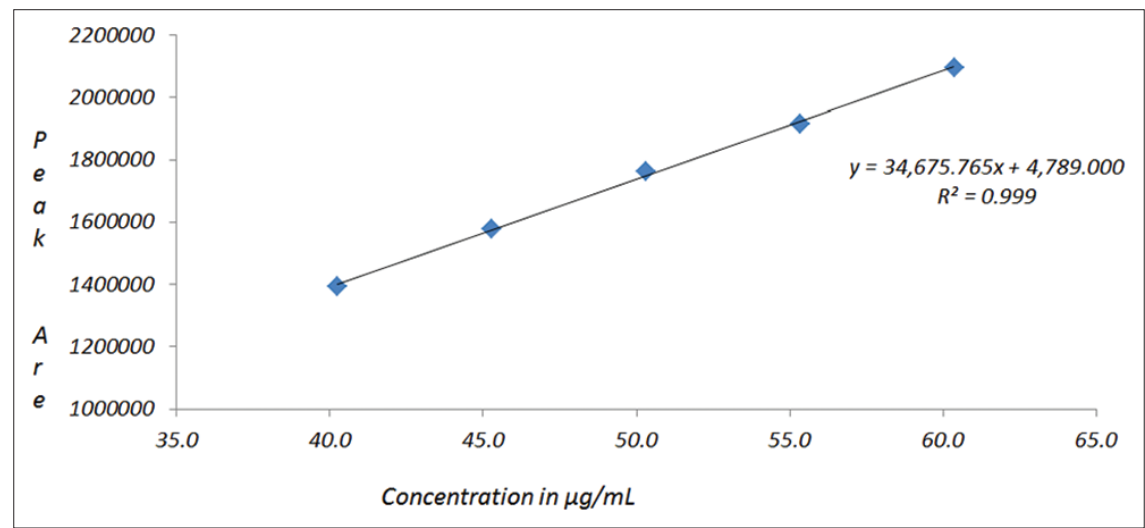

Fig. 8: Linearity curve for benzalkonium chloride

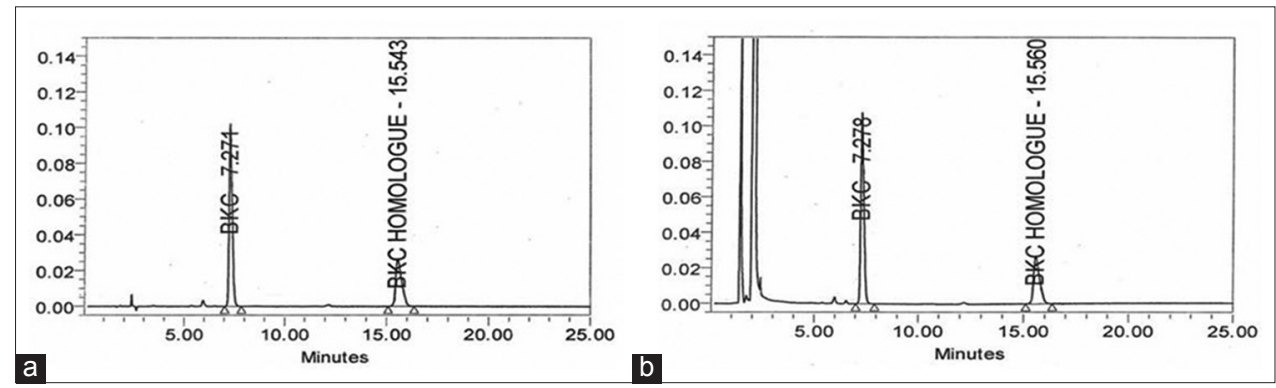

Fig. 9: Representative chromatogram of (a) standard control (b) test control

Table 4: Method accuracy for BKC determination

\begin{tabular}{|c|c|c|c|c|c|c|}
\hline \multirow[t]{2}{*}{ Accuracy level (\%) } & \multirow{2}{*}{$\begin{array}{l}\text { Theoretical } \\
\text { concentration (actual } \\
\text { amount added in } \mu \mathrm{g} / \mathrm{ml} \text { ) }\end{array}$} & $\begin{array}{l}\text { Experimental } \\
\text { concentration }\end{array}$ & \multirow[t]{2}{*}{ Recovery (\%) } & \multirow[t]{2}{*}{ Average (\%) } & \multirow[t]{2}{*}{$\%$ RSD } & \multirow[t]{2}{*}{ Overall RSD } \\
\hline & & $\begin{array}{l}\text { Actual amount } \\
\text { recovered in }(\mu \mathrm{g} / \mathrm{ml})\end{array}$ & & & & \\
\hline \multirow[t]{3}{*}{70} & 32.69 & 32.22 & 98.6 & & & \\
\hline & & 32.34 & 98.9 & 99.2 & 0.75 & \\
\hline & & 32.69 & 100.0 & & & \\
\hline \multirow{2}{*}{100} & & 46.37 & 99.3 & 100.7 & 1.20 & 0.82 \\
\hline & & 47.20 & 101.1 & & & \\
\hline \multirow[t]{3}{*}{130} & 60.71 & 61.64 & 101.5 & & & \\
\hline & & 61.77 & 101.8 & 101.4 & 0.50 & \\
\hline & & 61.22 & 100.8 & & & \\
\hline
\end{tabular}

RSD: Relative standard deviation, BKC: Benzalkonium chloride 
Table 5: Results of robustness conditions

\begin{tabular}{|c|c|c|c|c|c|c|}
\hline \multirow[t]{2}{*}{ HPLC condition } & \multicolumn{2}{|c|}{ Tailing factor } & \multicolumn{2}{|c|}{ Theoritical plates } & \multicolumn{2}{|l|}{ \%RSD } \\
\hline & Peak 1 & Peak 2 & Peak 1 & Peak 2 & Peak 1 & Peak 2 \\
\hline Controlled condition & 1.83 & 1.63 & 9881 & 13033 & 0.21 & 0.26 \\
\hline Column temperature plus & 1.68 & 1.58 & 9883 & 13974 & 0.86 & 0.97 \\
\hline Flow rate minus $1.35 \mathrm{ml} / \mathrm{minute}$ & 1.82 & 1.64 & 9631 & 13259 & 0.63 & 0.62 \\
\hline Flow rate plus $1.65 \mathrm{ml} / \mathrm{minute}$ & 1.69 & 1.58 & 9030 & 123606 & 0.84 & 0.67 \\
\hline $\mathrm{PH}$ of buffer 4.8 & 1.86 & 1.63 & 9293 & 12556 & 0.54 & 0.36 \\
\hline $\mathrm{pH}$ of buffer 5.2 & 1.83 & 1.66 & 9721 & 12737 & 0.46 & 0.57 \\
\hline Organic plus & 1.76 & 1.6 & 10015 & 13217 & 0.39 & 0.72 \\
\hline Organic minus & 1.91 & 1.65 & 9324 & 12583 & 0.54 & 0.59 \\
\hline
\end{tabular}

Table 6: Results of forced degradation study

\begin{tabular}{lllll}
\hline Stress condition & BKC assay & \% degradation & Peak purity (Peak 1) & Peak purity (Peak 2) \\
\hline Control condition & 99.4 & - & Passes & Passes \\
Acid degradation & 98.6 & 0.8 & Passes & Passes \\
Alkali degradation & 94.0 & 5.4 & Passes & Passes \\
Oxidative degradation & 98.0 & 1.4 & Passes & Passes \\
Thermal degradation & 98.7 & 0.7 & Passes & Passes \\
\hline
\end{tabular}

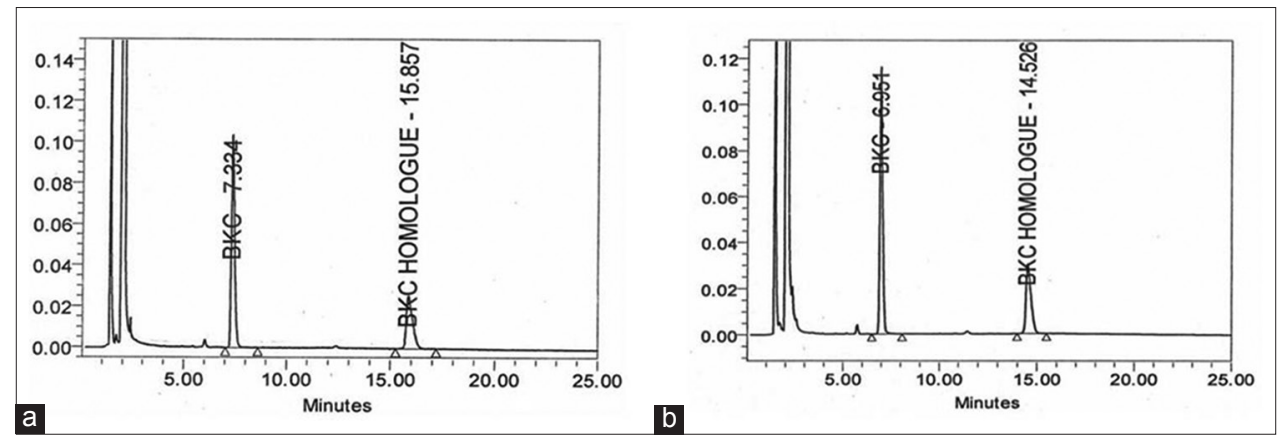

Fig. 10: Representative chromatogram of (a) temperature minus, (b) temperature plus

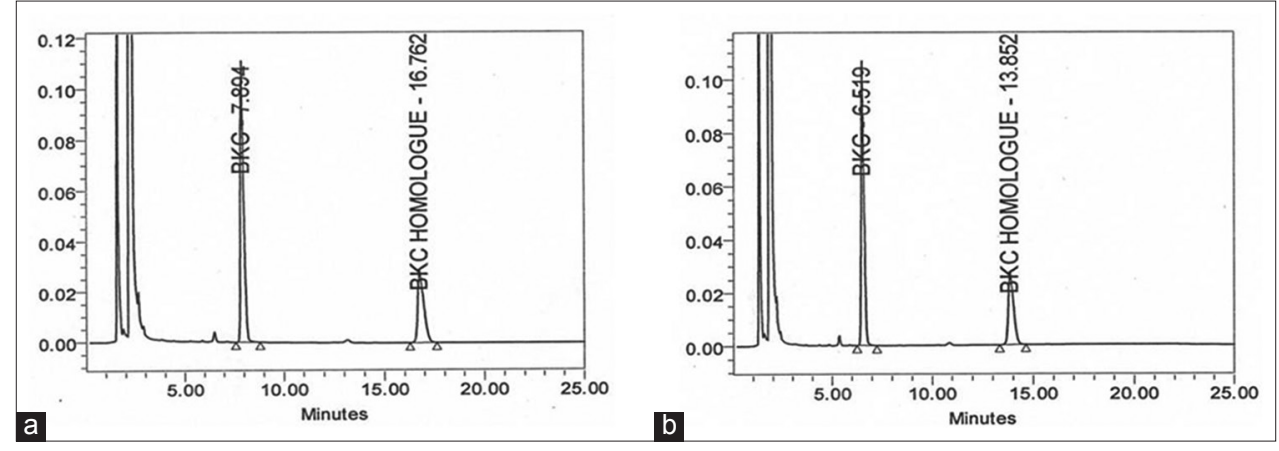

Fig. 11: Representative chromatogram of (a) flow minus, (b) flow plus

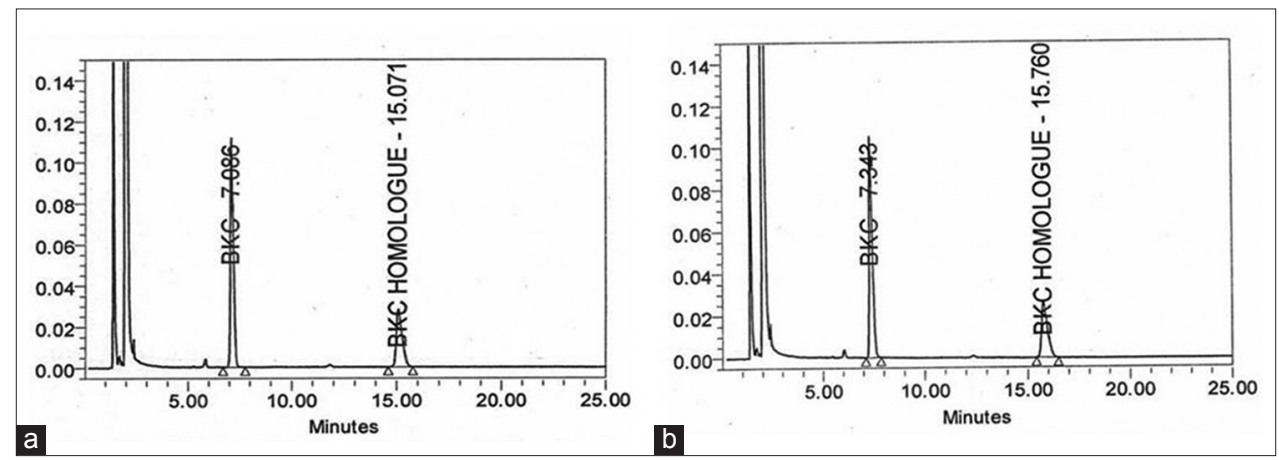

Fig. 12: Representative chromatogram (a) pH minus, (b) pH plus 


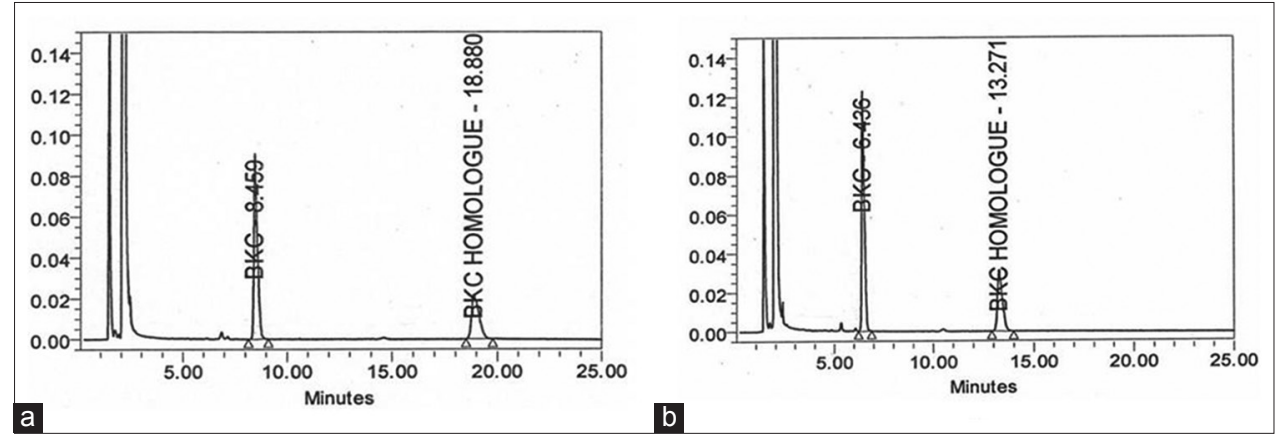

Fig. 13: Representative chromatogram of (a) organic minus, (b) organic plus

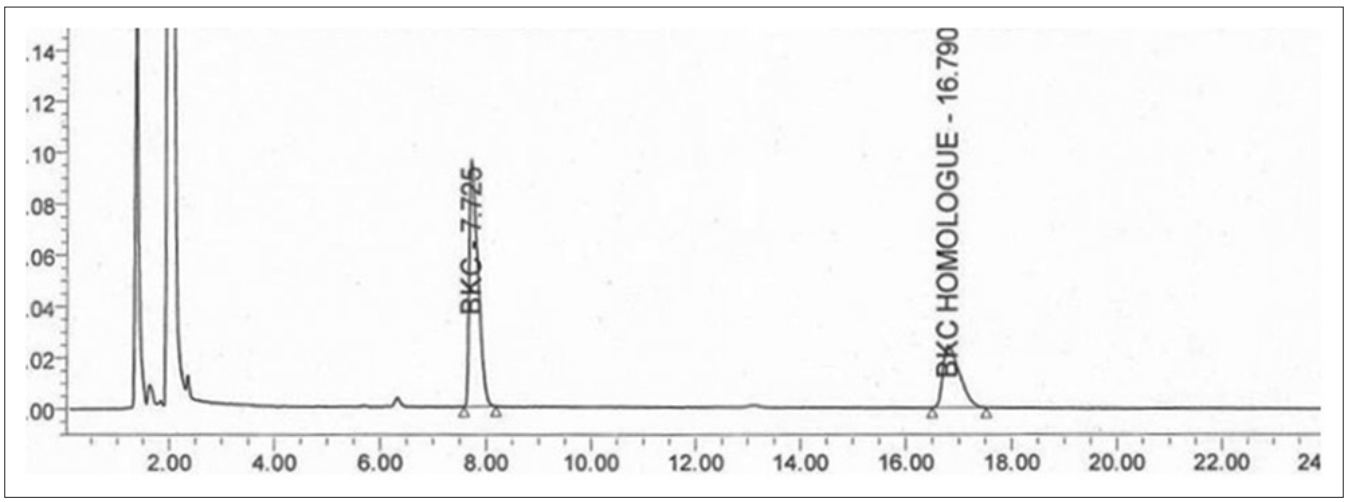

Fig. 14: Representative chromatogram for control sample

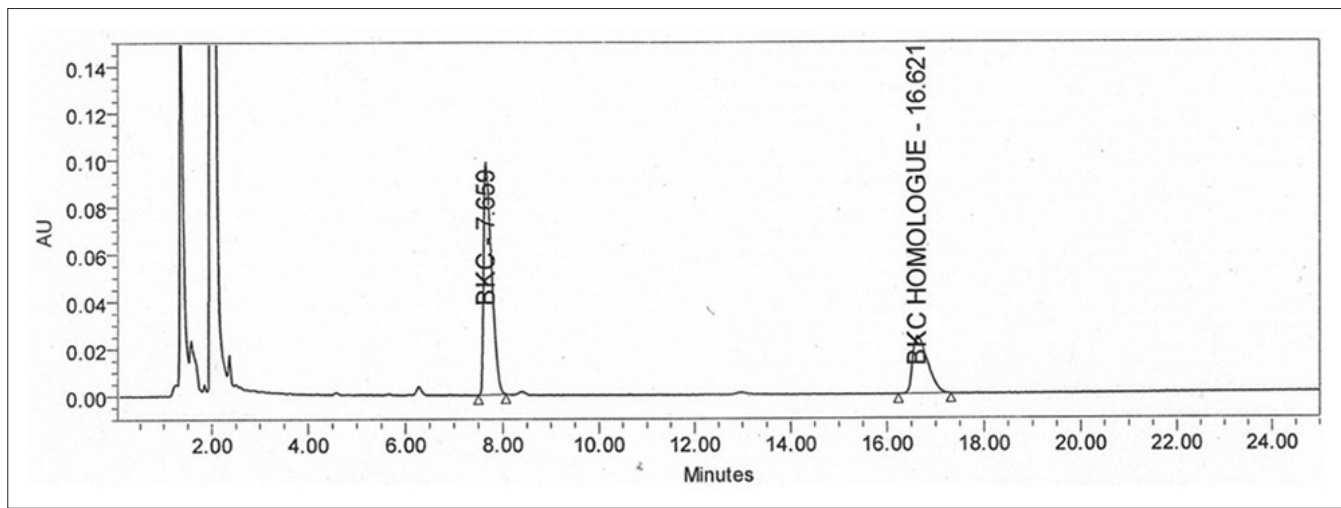

Fig. 15: Representative chromatogram for acid degradation sample

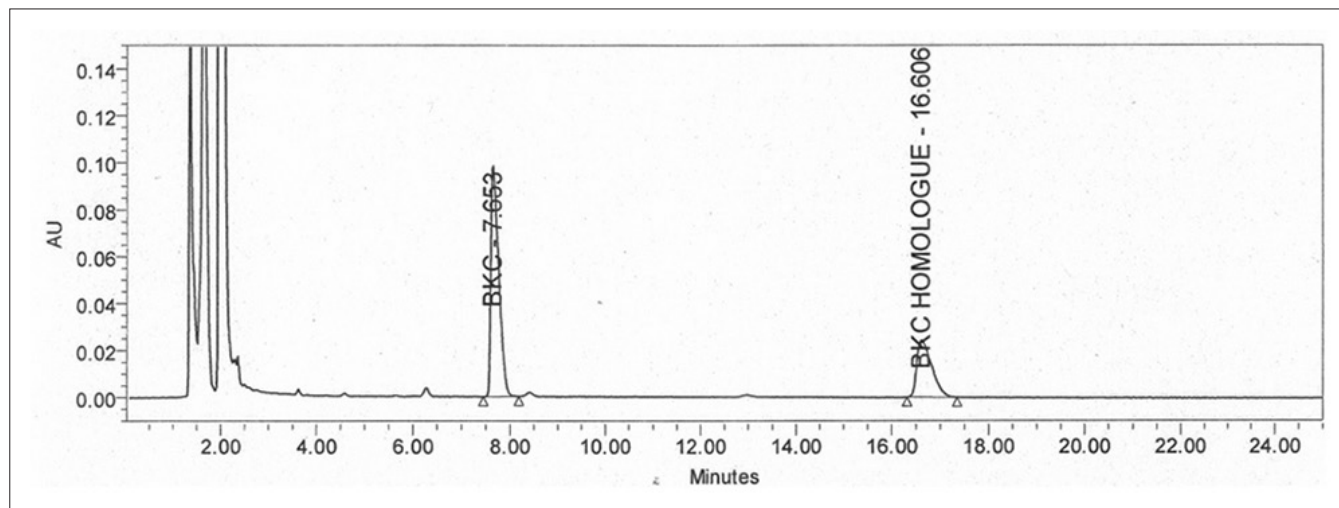

Fig. 16: Representative chromatogram for alkali degradation sample 


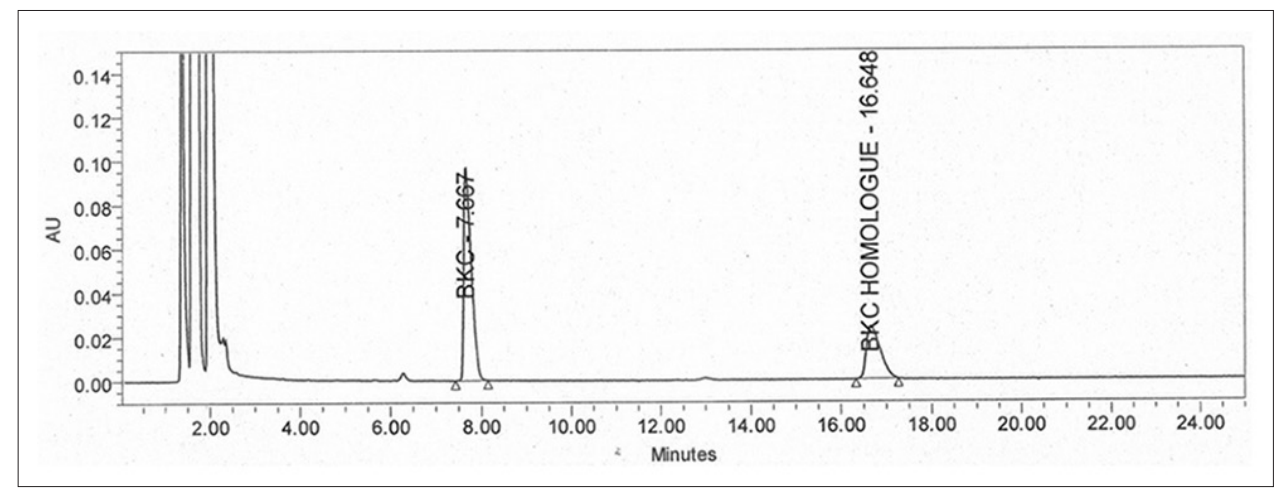

Fig. 17: Representative chromatogram for peroxide degradation

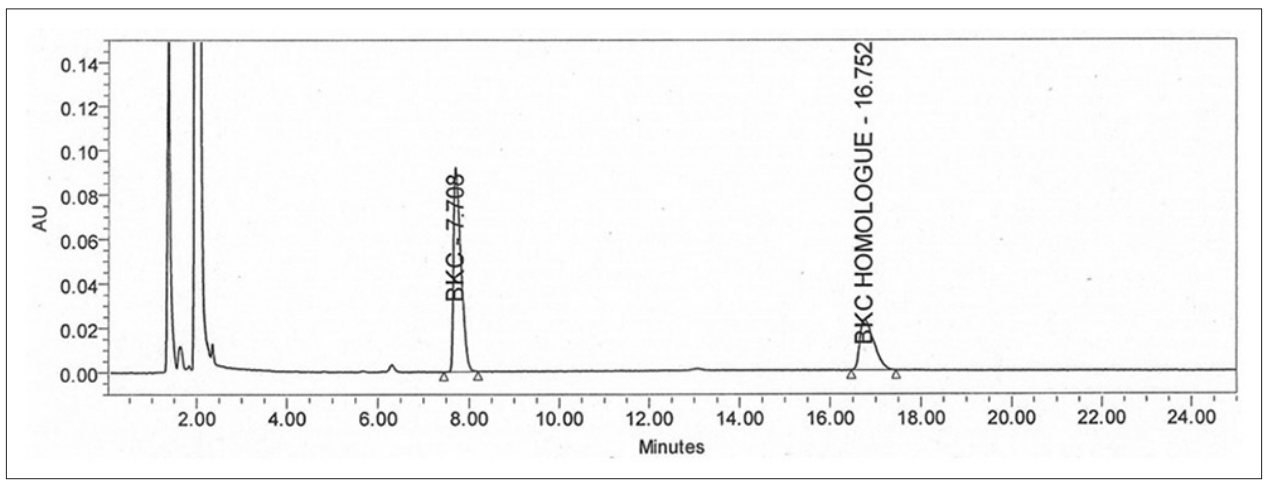

Fig. 18: Representative chromatogram for thermal degradation

\section{CONCLUSION}

This study presents a simple, reverse phase-stability indicating HPLC method for determination of benzalkonium chloride as major homologs in azelastine hydrochride pharmaceutical ophthalmic formulation. The developed and validated method is specific, selective, precise, linear, accurate, and robust. All the degradation products were well separated from analyte peaks demonstrating that the developed method was specific and stability indicating. This method stability indicating because of its successful evaluation of forced degradation studies. The validation study indicates that this method can be considerable for quantification of BKC in azelastine hydrochloride ophthalmic formulation.

\section{REFERENCES}

1. Baudouin C, Labbé A, Liang H, Pauly A, Brignole-Baudouin F. Preservatives in eyedrops: The good, the bad and the ugly. Prog Retin Eye Res 2010;29(4):312-34.

2. United States Pharmacopeia. USP 40-NF35. Benzalkonium Chloride; 2017. p. 7531-5.

3. Liu J, Lu GW, Sandoval M, Ciringh Y, Xue G, Jaeger D, et al. Determination of benzalkonium chloride partition in micelle solutions using ultrafiltration method. AAPS PharmSciTech 2009;10(4):1216-23.

4. Nelson L, Goldfrank L. Goldfrank's Toxicologic Emergencies. $9^{\text {th }}$ ed. New York: McGraw-Hill Medical; 2011.

5. Marple B, Roland P, Benninger M. Safety review of benzalkonium chloride used as a preservative in intranasal solutions: An overview of conflicting data and opinions. Off J Am Acad Otolaryngol Head Neck Surg 2004;130:131-41.

6. Azelastine Hydrochloride Ophthalmic Solution. 0.05\%, OPTIVAR ${ }^{\text {TM}}$; 2000. Available from: http://www.accessdata.fda.gov/drugsatfda_docs/ label/2000/21127lbl.pdf

7. Agarwal A, Tiwari S, Nagariya K. Method development and its validation for quantitative simultaneous determination of latanoprost, timolol and benzalkonium chloride in ophthalmic solution by RPHPLC. J Drug Deliv Ther 2013;3(2):26-30.

8. Al-Fakhory AA, Al-Kalak I, Al-Khatib MJ. Chromatographic determination of total benzalkonium chloride [BAC] in some of ophthalmic preparations by HPLC. Damascus Univ J Basic Appl Sci
2014;30:155-71.

9. Chiapetta SC, de Oliveira EC, Olivier BC, Mercante LA, Henriques DM, Pereira Netto AD. Intralaboratory validation, comparison and application of HPLC-UV-DAD methods for simultaneous determination of benzalkonium chloride, chlorexidine digluconate and triclosan. J Braz Chem Soc 2011;22(10):1913-20.

10. Murnane D, Martin G, Marriot C. Validation of reverse phase HPLC method for concurrent assay of weak base and pharmacologically active steroid. J Pharm Biomed Anal 2006;40:1149-54.

11. Gaber M, Shawish HM, Khedr AM, Abed-Almonem KI. Determination of benzalkonium chloride preservative in pharmaceutical formulation of eye and ear drops using new potentiometric sensors. Mater Sci Eng C 2012;32(8):2299-305.

12. Jovovic M, Kostic N, Jancic-Stojanovic B, Malenovic A. Investigation of tropicamide and benzalkonium chloride stability using liquid chromatography. J Liq Chromatogr Relat Technol 2012;32:231-9.

13. Kapakayala SV, Mubeen G, Kimbahune R. Reverse phase-high performance liquid chromatographic method for quantitation of epinastine hydrochloride in eye drops. Indo Am J Pharm Res 2013;3:7541-8.

14. Kostic DA, Mitic SS, Naskovic DC, Zarubica AR, Mitic MN. Determination of benzalkonium chloride in nasal drops by highperformance liquid chromatography. J Chem 2012;9(3):1599-604.

15. Mehta J, Patidar K, Vyas N. Development and validation of a precise method for determination of benzalkonium chloride (BKC) preservative, in pharmaceutical formulation of latanoprost eye drops. J Chem 2010;7:11-20.

16. Rao PV, Venkatesh P, Kumar MR. Validated stability indicating UPLC method for the estimation of benzalkonium chloride in ketorolac tromethamine ophthalmic solution. Int J Chrom Sci 2013;3:5-9.

17. Santos M, Li M, Rustum AM. A single RP-LC method for the determination of benzalkonium chloride and its potential impurities in benzalkonium chloride raw material. Chromatographia 2010;71(5-6):499-503.

18. Shaikh KA, Patil AT. Stability-indicating HPLC method for the determination of mometasone furoate, oxymetazoline, phenyl ethanol and benzalkonium chloride in nasal spray solution. J Trace Anal Food Drugs 2013;1:14-21.

19. Shen Y, Xu SJ, Wang SC, Tu JS. Determination of benzalkonium chloride in viscous ophthalmic drops of azithromycin by high-performance 
liquid chromatography. J Zhejiang Univ Sci B 2009;10(12):877-82.

20. Trivedi HK, Patel C. Development and validation of a precise and stability indicating LC method for the determination of benzalkonium chloride in pharmaceutical formulation using an experimental design. J Chem 2010;7:1514-22.

21. Trivedi RK, Challa S, Patel MC, Trivedi DR, Chatrabhuji PM. A rapid, stability-indicating RP-UPLC method for the simultaneous determination of fluticasone furoate and benzalkonium chloride in a pulmonary drug product. Chem Sci Trans 2013:2:1184-91.

22. Dudkiewicz-Wilczynska J, Tautt J, Roman I. Application of the HPLC method for benzalkonium chloride determination in aerosol preparations. J Pharm Biomed Anal 2004;34(5):909-20.

23. Labranche LP, Dumont SN, Levesque S, Carrier A. Rapid determination of total benzalkonium chloride content in ophthalmic formulation. J Pharm Biomed Anal 2007:43(3):989-93.

24. International Conference of Harmonization. ICH Harmonized Tripartite Guideline Validation of Analytical Procedures: Text and Methodology
Q2(R1). Geneva: ICH; 2005.

25. Daravath B, Reddy G, Kamarapu SK. Development and validation of RP-HPLC for simultaneous estimation of chlormepheniramine maleate and diethylcarbamzine citrate in pharmaceutical dosage forms. Asian J Pharm Clin Res 2014;7:98-102

26. Deshpande PB, Butle SR. Development and validation of stability indicating HPTLC method for determination of darunavir ethanolate and ritonavir. Int J Pharm Pharm Sci 2015;7:66-71.

27. Patil PM, Bobade AS. Development and validation of stability indicating RP-HPLC for determination of atorvastatin calcium and ezetimibe in bulk and pharmaceutical dosage forms. Int J Pharm Pharm Sci 2016;8:38-42.

29. Cione AP, Tonhi E, Silva P. Stability Indicating Methods. Brazil: Bioagri Laboratórios, Intech; 2011.

30. Al-Aani H, Al-Nukkary Y. Determination of benzalkonium chloride in ophthalmic solution by stability indicating HPLC method: Application to a stability study. J Appl Pharm Sci 2016;6:80-9. 